\title{
Youth mental health in the time of COVID-19
}

\author{
E. Power ${ }^{1 * *}$ (iD , S. Hughes ${ }^{2}$, D. Cotter ${ }^{1,3}$ and M. Cannon ${ }^{1,3,4}$ \\ ${ }^{1}$ Department of Psychiatry, Royal College of Surgeons in Ireland, Smurfit Building, Beaumont Hospital, Beaumont Road, Dublin 9, Ireland \\ ${ }^{2}$ Union of Students of Ireland, 14 Mount Street Upper, Dublin 2, Ireland \\ ${ }^{3}$ Department of Psychiatry, Beaumont Hospital, Dublin 9, Ireland \\ ${ }^{4}$ Trinity College Institute of Neuroscience, Lloyd Building, Trinity College Dublin, Dublin 2, Ireland
}

\begin{abstract}
Youth mental health is a rapidly developing field with a focus on prevention, early identification, treatment innovation and service development. In this perspective piece, we discuss the effects of COVID-19 on young people's mental health. The psychosocial effects of COVID-19 disproportionately affect young people. Both immediate and longer-term factors through which young people are affected include social isolation, changes to the delivery of therapeutic services and almost complete loss of all structured occupations (school, work and training) within this population group. Longer-term mechanisms include the effects of the predicted recession on young people's mental health. Opportunities within this crisis exist for service providers to scale up telehealth and digital services that may benefit service provision for young people's mental health in the future.
\end{abstract}

Received 13 May 2020; Revised 23 June 2020; Accepted 25 June 2020; First published online 02 July 2020

Key words: COVID-19, digital, youth mental health.

\section{Introduction}

Mental disorders are the largest cause of years lived with disability worldwide (Whiteford et al. 2015). Up to $80 \%$ of mental disorders first occur before the age of 26 (Caspi et al. 2020; Kessler et al. 2005). Earlier age of onset of mental disorder is associated with increased risks of development of comorbidity and persistence of mental health disorder to midlife (Caspi et al. 2020). Young people who remain free of mental disorder have longitudinally better outcomes (Caspi et al. 2020). Youth mental health problems cast a long shadow over adult health and psychosocial functioning. The magnitude of the effects of mental health problems in youth over the life course far surpasses the effects of early physical health problems (Goodman et al. 2011). In this paper, we will outline how youth, whilst less susceptible to severe COVID-19 infection, is more at risk of the negative psychosocial effects of the pandemic that was officially declared on the 11th of March 2020 (Holmes et al. 2020).

\section{Disrupted transitions}

Entering the labour force from education marks one of the most significant transitions that takes place during a young person's life, and this transition has become more complex in recent decades (Arnett 2000). During recent periods of economic recession, young

*Address for correspondence: Dr. E. Power, Department of Psychiatry, Royal College of Surgeons in Ireland, Smurfit Building, Beaumont Hospital, Beaumont Road, Dublin 9, Ireland.

(Email: emmetpower@rcsi.com) people have much higher rates of unemployment (Bell and Blanchflower, 2011). The effects of periods of unemployment in youth have disproportionate and long-lasting effects on income and health beyond the period of economic recession as well as risks of concurrent and future insecure employment (Kahn, 2010; Cockx, 2016). Currently, a majority of young people (51\%) between the ages 15-24 within the labour force (i.e. those available for work and not in education) are unemployed in Ireland (CSO, 2020). This represents almost 2.5 times the unemployment rate in adults and almost 2.5 times the peak unemployment rate in the same age reference category during the most recent economic recession (CSO, 2020). Analysis from the Economic and Social Research Institute predicts Ireland to experience a severe economic recession in the coming year (McQuinn et al. 2020). In periods of recession, more highly educated youths have moderate long-lasting reductions in income for at least a period of 10 years, whilst losses are restored for lower educated youths more quickly (Cockx, 2016). Graduating from university during a recession has particular long-lasting and large impacts on earning potential (Kahn, 2010). During periods of recession, high educational level may not be a protective for young people's mental health and may be a risk factor for poor mental health outcomes specifically when youth are engaged in insecure working arrangements or are unemployed. One recent study from Italy suggests that young highly educated women are at most increased risk of poorer mental health due to economic insecurity during periods of recession (Fiori et al. 2016). Economic inactivity (i.e. not being in employment education or training) 
increases risks of suicidal thoughts and behaviours in young people beyond the effects of prior mental health vulnerability (Power et al. 2015). The mental health effects of unemployment in youth persist to midlife with those exposed to unemployment in youth having increased rates of common mental health symptoms like anxiety and depression on long-term follow-up (Virtanen et al. 2016).

Youth is also a point of cognitive, social and emotional transitions. Young people, particularly adolescents, have different cognitive approaches to making social decisions in comparison to adults (Blakemore \& Choudhury, 2006). Social connectedness and social identity have more prominence in youth and high rates of reported loneliness are reported in young people (Matthews et al. 2019). Loneliness in young adults is associated with a number of negative health behaviours and indicators of poor mental health independent of other risk factors (Matthews et al. 2019). In this context, young people may be more affected by the negative psychosocial consequences of 'lockdown' and social distancing than adults. Young people may also find it more difficult to cope with the current crisis as their coping skills are not equivalent to that of a fully-fledged adult as coping is a developmentally acquired skill (Fields \& Prinz, 1997).

\section{An acute on chronic public health crisis}

Investing in early intervention in mental health has potential to reduce population level chronic disease morbidity. Early intervention programmes in psychosis show reductions in mortality and improvements in significant and pragmatic indicators of psychosocial functioning (McGorry, 2015; Pollard et al. 2020). Despite these innovations, new service models for psychosis are only selectively available to a small proportion of the population depending on geographical area. Early intervention for other specific serious mental disorders is in earlier phases of development (Chanen et al. 2017; Vieta et al. 2018). Early intervention services for adolescents and young people at primary care level (such as Jigsaw in Ireland and Headspace in Australia) are also being rolled out in line with international best practice (Hetrick et al. 2017; McGorry et al. 2013). Despite new and evolving evidence in youth mental health, resource allocation for young people's mental health remains insufficient. A recent survey of Child and Adolescent Mental Health Services consultants showed high levels of burnout (McNicholas et al. 2020). Known precipitants to this are insufficient staffing, incomplete coverage and long waiting lists (McNicholas, 2018). Incomplete coverage is a specific issue for primary care services such as Jigsaw. In this current pandemic crisis, educational, health and social care services have had to curtail the level of service offered to young people and their families. This COVID-19 pandemic presents an 'acute on chronic crisis' for services for young people where demand on services is likely to increase but supply of services is further constrained and inconsistent.

Ensuring the material needs and physical health of communities is the immediate priority in any public health emergency, conflict situation or natural disaster. The mental health needs of young people can be overlooked in a public health crisis (Danese et al. 2020). There are worries for a 'final wave' of the effects of the virus in terms of the negative mental health and social consequences borne by young people whom have little control over their environmental circumstances. There are many potential adverse consequences for young people who have lost access to structured school and college and work environments. There are broad physical and mental health implications for all young people. Negative physical health consequences such as poorer sleep, poorer diet, increased sedentary behaviour and loss of cardiometabolic fitness are more common and these are likely to relate to poorer mental health during COVID (Wang et al. 2020). However, the mental health consequences may be more significant and long lasting. Early survey reports from China highlight the negative mental health consequences of exposure to the pandemic in young people, reporting increased rates of anxiety, poorer sleep and irritability (Jiao et al. 2020).

The mental health impacts of any disaster are unevenly distributed. Those with lower social capital and those in vulnerable positions are most at risk. One example is young people in temporary accommodation or direct provision. These groups of individuals and their family members face an already higher burden of mental health risk as well as direct increased risks of COVID infection due to unsuitable accommodation (Rosenthal et al. 2020). Reports of increased rates of exposure to domestic violence are concern for vulnerable young people also (Gunnell et al. 2020; Chandan et al. 2020). Public institutions buffer the effect, length and severity of childhood adversity and trauma. This is through a multitude of mechanisms such as providing free school meals, providing a physically safe environment for part of the day through school participation, support through voluntary services and mandated child welfare/ protection reporting. Access to a supportive adult is a protective factor for a young person's mental health and some will have lost this protective factor during this crisis through loss of supports outside the family home (Dooley et al. 2015). In this context, prioritizing equity in reopening services is important. Services, such as school placements, should be provided for the most vulnerable young people first. 
Early research efforts from the YoungMinds organisation in the UK highlight the predominance of concerns around the psychological and social consequences of the pandemic response, particularly on young people (YoungMinds, 2020; Holmes et al. 2020). In this recent UK survey, $83 \%$ of young people with mental health needs believed that COVID-19 had an adverse impact on their mental health, with specific concerns around loss of social contact and structured activities. In this survey, young people with varying types of mental health conditions, such as obsessive compulsive disorder, anxiety disorders and anorexia nervosa specifically noted that the crisis had worsened their pre-existing conditions. One in four young people whom had been accessing mental health supports prior to the pandemic reported that they no longer had access because of the crisis (YoungMinds, 2020).

\section{Research priorities}

The effects of mandated self-isolation in terms of morbidity and mortality of young people most at risk of negative health consequences of the pandemic should be a primary focus of research. Existing cohort studies should be leveraged to investigate the changes in health status in youth during the time of COVID (Holmes et al. 2020). The World Health Organisation recommends that the mental health needs of young people should be included within coordinated statutory disaster response mechanisms through at minimum the dissemination of psychoeducational and self-help resources for young people to promote universal advice on maintaining positive health behaviours (World Health Organisation, 2020). Simple guidance on addressing young people's concerns with age appropriate emotionfocused language is highly likely to be significantly effective (Dalton et al. 2020). Guidance for caregivers on the positive impact of maintaining their own well-being is also important. Young people's mental health is strongly influenced by the well-being of their caregivers. Evidencebased digital platforms, such as interventions targeting disruptive behaviour in children, may benefit in being rolled out at this time. They are effective in reducing target symptoms and secondary care utilisation after 2-year follow-up (McGrath et al. 2013; Sourander et al. 2018).

\section{Opportunities for change}

Opportunities for positive change exist at many levels, for some individual young people, for families, for health and social care professionals and researchers, for communities and for specific sectors. Many young people will have unique opportunities to spend more time with their families and a small minority $(8 \%)$ in the YoungMinds survey reported this (YoungMinds,
2020). For caregivers working from home or temporarily furloughed, current remote working arrangements could offer opportunities for longer-term flexible working conditions that are common in many Nordic countries and appear to have a well-being dividend for young people and their families (Caan \& Jenkins 2008). The current crisis may also be an opportunity to investigate the effects of community cohesion on prosocial behaviours, psychopathology and suicidality in young people (Oosterhoff et al. 2020).

Opportunities exist for health care professionals to change work practices to rapidly scale up effective digital and digital-hybrid interventions. Whilst digital interfaces in mental health can be effective, clinician resistance is cited as hindering widespread uptake (Wind et al. 2020). Telepsychiatry is broadly acceptable to a large majority of young people with severe mental disorders such as psychosis, with some caveats around potentially increased dropout from treatment (Lal et al. 2020). Digital platform development is specifically important for youth as young people are digital natives who look online first for information related to their mental health. Emerging platforms offer partially guided adaptations of standard therapies (such as cognitive behavioural therapy) through video games (Chapman et al. 2016). These are scalable, effective and youth-friendly alternatives to traditional therapies. Emerging digital services offer a democratisation of access to emerging and specialist therapies, for example, in depression and psychosis in young people (Rice et al. 2018; McEnery et al. 2019). Digital services have many practical advantages, as access to services is contingent on geography, particularly in Ireland. One positive outcome of the pandemic is that clinicians and patients have had the opportunity to use digital or tele-platforms where previously this option would not have been available to them. Digital platforms have potential to improve quality of care particularly in non-urban areas where there may be no or insufficient access to services locally. Digital services may also reduce costs associated with obtaining mental health care for young people and their caregivers.

In conclusion, we have discussed why the COVID19 pandemic will disproportionately affect young people both in the short- and long-term, and why the harms of the pandemic at a population level are inequitably distributed. The COVID-19 pandemic will however be a catalyst to rethink the delivery of services and to provide more accessible, equitable and efficient services in the future.

\section{Financial support}

Health Research Board 'YouLead' Collaborative Doctoral Award (Grant code 18210A01) supports EP. European 
Research Council Consolidator Award (Grant code 724809 iHEAR) supports MC. Health Research Board ILP POR 2017-039 and Health Research Board ILP POR 2019-0005 support DC.

\section{Conflict of interest}

Authors have no conflicts of interest to declare.

\section{Ethical standards}

The authors assert that all procedures contributing to this work comply with the ethical standards of the relevant national and institutional committee on human experimentation with the Helsinki Declaration of 1975, as revised in 2008. The authors assert that ethical approval for publication of this paper was not required by their local Ethics Committee.

\section{References}

Arnett JJ (2000). Emerging adulthood: a theory of development from the late teens through the twenties. American Psychologist 55, 469.

Bell DN, Blanchflower DG (2011). Young people and the Great Recession. Oxford Review of Economic Policy 27, 241-267.

Blakemore SJ, Choudhury S (2006). Development of the adolescent brain: implications for executive function and social cognition. Journal of Child Psychology and Psychiatry 47, 296-312.

Caan W, Jenkins R (2008). Integrating the promotion of child mental health into national policies for health sector reform. Journal of Public Mental Health 7, 9.

Caspi A, Houts RM, Ambler A, Danese A, Elliott ML, Hariri A et al. (2020). Longitudinal assessment of mental health disorders and comorbidities across 4 decades among participants in the Dunedin birth cohort study. JAMA Network Open 3, e203221-e203221.

Chandan JS, Taylor J, Bradbury-Jones C, Nirantharakumar K, Kane E, Bandyopadhyay S (2020). COVID-19: a public health approach to manage domestic violence is needed. The Lancet Public Health 5, e309.

Chanen A, Sharp C, Hoffman P, the Global Alliance got Early Intervention for Borderline Personality (2017). Prevention and early intervention for borderline personality disorder: a novel public health priority. World Psychiatry 16, 215-216.

Chapman R, Loades M, O'Reilly G, Coyle D, Patterson M, Salkovskis P (2016). 'Pesky gNATs': investigating the feasibility of a novel computerized CBT intervention for adolescents with anxiety and/or depression in a Tier 3 CAMHS setting. The Cognitive Behaviour Therapist, 9.

Cockx B (2016). Do youths graduating in a recession incur permanent losses? IZA World of Labor. doi: 10.15185/ izawol.281

CSO (2020). Statistical Release Monthly Unemployment. Dublin: Central Statistics Office. Retrieved from: https:// www.cso.ie/en/releasesandpublications/er/mue/ monthlyunemploymentmay2020/
Dalton L, Rapa E, Stein A (2020). Protecting the psychological health of children through effective communication about COVID-19. The Lancet Child \& Adolescent Health 4, 346-347.

Danese A, Smith P, Chitsabesan P, Dubicka B (2020). Child and adolescent mental health amidst emergencies and disasters. British Journal of Psychiatry 216, 159-162. doi: 10.1192/bjp.2019.244

Dooley B, Fitzgerald A, Giollabhui N (2015). The risk and protective factors associated with depression and anxiety in a national sample of Irish adolescents. Irish Journal of Psychological Medicine 32, 93-105.

Fields L, Prinz RJ (1997). Coping and adjustment during childhood and adolescence. Clinical Psychology Review 17, 937-976.

Fiori F, Rinesi F, Spizzichino D, Di Giorgio G (2016). Employment insecurity and mental health during the economic recession: an analysis of the young adult labour force in Italy. Social Science $\mathcal{E}$ Medicine 153, 90-98.

Goodman A, Joyce R, Smith JP (2011). The long shadow cast by childhood physical and mental problems on adult life. Proceedings of the National Academy of Sciences 108, 6032-6037.

Gunnell D, Appleby L, Arensman E, Hawton K, John A, Kapur N, et al. (2020). Suicide risk and prevention during the COVID-19 pandemic. The Lancet Psychiatry 7, 468-471.

Hetrick SE, Bailey AP, Smith KE, Malla A, Mathias S, Singh SP, et al. (2017). Integrated (one-stop shop) youth health care: best available evidence and future directions. Medical Journal of Australia 207, S5-S18.

Holmes EA, O'Connor RC, Perry VH, Tracey I, Wessely S, Arseneault L, et al. (2020). Multidisciplinary research priorities for the COVID-19 pandemic: a call for action for mental health science. The Lancet Psychiatry 7, 547-560. doi: 10.1016/S2215-0366(20)30168-1

Jiao WY, Wang LN, Liu J, Fang SF, Jiao FY, PettoelloMantovani M, Somekh E (2020). Behavioral and emotional disorders in children during the COVID-19 epidemic. The Journal of Pediatrics, 221, 264-266.e1. doi: $10.1016 /$ j.jpeds.2020.03.013

Kahn LB (2010). The long-term labor market consequences of graduating from college in a bad economy. Labour Economics 17, 303-316.

Kessler RC, Berglund P, Demler O, Jin R, Merikangas KR, Walters EE (2005). Lifetime prevalence and age-of-onset distributions of DSM-IV disorders in the National Comorbidity Survey Replication. Archives of General Psychiatry 62, 593-602.

Lal S, Abdel-Baki A, Sujanani S, Bourbeau F, Sahed I, Whitehead J (2020). Perspectives of young adults on receiving telepsychiatry services in an urban early intervention program for first-episode psychosis: a cross-sectional, descriptive survey study. Frontiers in Psychiatry 11, 117.

Matthews T, Danese A, Caspi A, Fisher HL, GoldmanMellor S, Kepa A, et al. (2019). Lonely young adults in modern Britain: findings from an epidemiological cohort study. Psychological Medicine 49, 268-277. 
McEnery C, Lim MH, Knowles A, Rice S, Gleeson J, Howell S, et al. (2019). Development of a moderated online intervention to treat social anxiety in first-episode psychosis. Frontiers in Psychiatry 10, 581.

McGrath PJ, Sourander A, Lingley-Pottie P, Ristkari T, Cunningham C, Huttunen J, et al. (2013). Remote population-based intervention for disruptive behavior at age four: study protocol for a randomized trial of Internet-assisted parent training (Strongest Families Finland-Canada). BMC Public Health 13, 985.

McGorry P, Bates T, Birchwood M (2013). Designing youth mental health services for the 21st century: examples from Australia, Ireland and the UK. British Journal of Psychiatry 202, s30-s35.

McGorry PD (2015). Early intervention in psychosis: obvious, effective, overdue. The Journal of Nervous and Mental Disease 203, 310.

McNicholas F (2018). Child \& adolescent emergency mental health crisis: a neglected cohort. Irish Medical Journal 111, 841.

McNicholas F, Sharma S, Oconnor C, Barrett E (2020). Burnout in consultants in child and adolescent mental health services (CAMHS) in Ireland: a cross-sectional study. BMJ Open 10, e030354.

McQuinn K, O' Toole C, Allen-Coghlan M, Coffey C (2020) Quarterly Economic Commentary, Summer 2020. ESRI Forecasting Series. https://doi.org/10.26504/qec2020sum

Oosterhoff B, Palmer CA, Wilson J, Shook N (2020). Adolescents' motivations to engage in social distancing during the COVID-19 pandemic: associations with mental and social health. Journal of Adolescent Health. https://doi. org/10.1016/j.jadohealth.2020.05.004

Pollard JM, Ferrara M, Lin I, et al. (2020). Analysis of early intervention services on adult judicial outcomes. JAMA Psychiatry. Published online 22 April 2020. doi: 10.1001/ jamapsychiatry.2020.0448

Power E, Clarke M, Kelleher I, Coughlan H, Lynch F, Connor D, et al. (2015). The association between economic inactivity and mental health among young people: a longitudinal study of young adults who are not in employment, education or training. Irish Journal of Psychological Medicine 32, 155-160.

Rice S, Gleeson J, Davey C, Hetrick S, Parker A, Lederman R, et al. (2018). Moderated online social therapy for depression relapse prevention in young people: pilot study of a 'next generation' online intervention. Early Intervention in Psychiatry 12, 613-625.

Rosenthal DM, Ucci M, Heys M, Hayward A, Lakhanpaul M 2020. Impacts of COVID-19 on vulnerable children in temporary accommodation in the UK. The Lancet Public Health 5, e241-e242.

Sourander A, McGrath PJ, Ristkari T, Cunningham C, Huttunen J, Hinkka-Yli-Salomäki S, et al. (2018). Twoyear follow-up of internet and telephone assisted parent training for disruptive behavior at age 4. Journal of the American Academy of Child \& Adolescent Psychiatry 57, 658-668.

Vieta E, Salagre E, Grande I, Carvalho AF, Fernandes BS, Berk M, et al. (2018). Early intervention in bipolar disorder. American Journal of Psychiatry 175, 411-426.

Virtanen P, Hammarström A, Janlert U (2016). Children of boom and recession and the scars to the mental health $-\mathrm{a}$ comparative study on the long term effects of youth unemployment. International Journal for Equity in Health 15, 14 .

Wang G, Zhang Y, Zhao J, Zhang J, Jiang F (2020). Mitigate the effects of home confinement on children during the COVID-19 outbreak. The Lancet 395, 945-947.

Whiteford HA, Ferrari AJ, Degenhardt L, Feigin V, Vos T (2015). The global burden of mental, neurological and substance use disorders: an analysis from the Global Burden of Disease Study 2010. PLoS One 10, e0116820.

Wind TR, Rijkeboer M, Andersson G, Riper H (2020). The COVID-19 pandemic: the 'black swan' for mental health care and a turning point for e-health. Internet Interventions 20, 100317.

World Health Organization. (2020) Mental health and psychosocial considerations during the COVID-19 outbreak. Geneva: World Health Organization. (https: / / www. who.int/docs/default-source/coronaviruse/mentalhealth-considerations.pdf?sfvrsn=6d3578af_2). Accessed 17 June 2020.

YoungMinds. (2020). Coronavirus: Impact on young people with mental health needs. London: YoungMinds. (https:// youngminds.org.uk/media/3708/coronavirusreportmarch2020.pdf). Accessed 17 June 2020. 